\title{
Overexpression of Protocadherin-10 in Transthyretin-Related Familial Amyloidotic Polyneuropathy
}

\author{
Nádia P. Gonçalves, ${ }^{* \dagger}$ Diana Martins, ${ }^{* \dagger}$ and Maria João Saraiva ${ }^{* \dagger}$ \\ From the Instituto de Inovação e Investigação em Saúde $(I 3 S) *$ and the Molecular Neurobiology Group,$^{\dagger}$ IBMC - Instituto de Biologia Molecular e Celular, \\ Universidade do Porto, Porto, Portugal
}

\author{
Accepted for publication \\ February 23, 2016. \\ Address correspondence to \\ Maria João Saraiva, Ph.D., \\ Molecular Neurobiology, i3S - \\ Instituto de Investigação e Ino- \\ vação em Saúde, Rua Alfredo \\ Allen, 208, 4200-135 Porto, \\ Portugal. E-mail: mjsaraiv@ \\ ibmc.up.pt.
}

\begin{abstract}
Overwhelming data suggest that oncogenic and neurodegenerative pathways share several altered cellular responses to insults such as oxidative stress, extracellular matrix remodeling, inflammation, or cell dyscommunication. Protocadherin-10 (Pcdh10) is an adhesion molecule found to protect against tumorigenesis and essential for axonal elongation and actin dynamics during development. Here, by using genome microarrays we identified for the first time Pcdh10 up-regulation in tissues from transgenic mouse models, cultured Schwann cells, and human samples from a familial form of peripheral neuropathy (familial amyloidotic polyneuropathy). Familial amyloidotic polyneuropathy is characterized by poor functional recovery and impaired nerve regenerative response after misfolding and deposition in the peripheral nervous system of mutant transthyretin. Not only increased transcriptional and translational Pcdh10 levels occurred in axons and Schwann cells of nerves with deposited transthyretin aggregates but the pattern also extended to associated cues of axon guidance like neuropilin-1 and F-actin. These findings suggest that Pcdh10 may influence subcellular actin cytoskeletal organization and axon-axon interactions in the course of familial amyloidotic polyneuropathy. Moreover, when preventing nonfibrillar transthyretin deposition with anakinra or transthyretin siRNA, Pcdh10 protein levels were reduced, highlighting its potential as a novel disease biomarker. Whether Pcdh10 overexpression in familial amyloidotic polyneuropathy represents a protective or deleterious response, enhancing survival or promoting cell death will need further investigation. (Am J Pathol 2016, 186: 1913-1924; http://dx.doi.org/10.1016/j.ajpath.2016.02.020)
\end{abstract}

Amyloidoses constitute a large group of rare disorders caused by extracellular deposition of insoluble misfolded proteins, ultimately disrupting normal tissue function. Transthyretin (TTR)-related amyloidosis is phenotypically heterogeneous and, although the major clinical feature is sensorimotor polyneuropathy, cardiomyopathy, carpal tunnel syndrome, vitreopathy, life-threatening autonomic dysfunction, or leptomeningeal involvement occur as well. ${ }^{2}$ More than 100 TTR variants have been identified, resulting from point substitutions in the polypeptide chain; the most common mutation associated with peripheral neuropathy is the replacement of a methionine for a valine at codon 30 (V30M). ${ }^{3}$ Familial amyloidotic polyneuropathy (FAP) was first described by Corino de Andrade in northern Portugal, and, despite being rare, the disease is distributed worldwide. ${ }^{5}$ The deposition of mutant TTR aggregates and amyloid fibrils, particularly in the peripheral nervous system (PNS), leads to axonal fiber degeneration together with invasion and destruction of endoneurial blood vessels. 6 Although the precise molecular mechanisms that mediate cytotoxicity in FAP are not yet fully understood, several pathways such as endoplasmic reticulum/oxidative stress,

\footnotetext{
Supported by FEDER funds through the Operational Competitiveness Program - COMPETE, by national funding from Portuguese Foundation for Science and Technology (FCT) under the project PTDC/BIM-MEC/ 0282/2012, a Ph.D. fellowship SFRH/BD/74304/2010 (N.P.G.), and a postdoctoral fellowship ON2-201302-ND-III (D.M.).

N.P.G. and D.M. contributed equally to this work.

Disclosures: Alnylam Pharmaceuticals (Boston) supplied the siRNA reagents.
} 
apoptosis, inflammation, and extracellular matrix remodeling were implicated in the pathogenesis of this neurodegenerative disorder. ${ }^{7}$ A striking feature of FAP is that, despite the presence of cytokine-driven neuroinflammation, no immune cellular infiltration is usually found near TTR deposits. $^{8,9}$ In addition, FAP Schwann cells present impaired production of agents that mediate regeneration such as neurotrophins and chemokines, accounting for neurodegeneration. $^{10,11}$ Thus, novel insights about FAP pathogenesis and mechanisms underlying nerve degeneration are paramount for the development of novel therapeutic strategies or disease follow-up biomarkers.

Protocadherins (Pcdhs) are a group of transmembrane proteins within the cadherin superfamily, divided into clustered and nonclustered proteins. ${ }^{12}$ Although cadherin family members are known to regulate cell-cell interactions, mainly cell-cell adhesion, the function of Pcdh remains elusive. ${ }^{13}$ Both clustered and nonclustered Pcdhs are expressed in the nervous system of developing vertebrates and may inclusively have important roles in the pathophysiology of tumorigenesis ${ }^{14,15}$ and different neurologic disorders, such as epilepsy, autism, or schizophrenia. ${ }^{16-19}$ Clustered Pcdhs are primarily associated with neuronal survival, and dendrite self-avoidance, whereas nonclustered proteins, such as Pcdh8, Pcdh10, Pcdh17, Pcdh18, and Pcdh19, promote cell motility and mediate dynamic cellular processes, such as growth cone migration. ${ }^{20} \mathrm{Pcdh} 10$ is also required for growth of striatal axons in mouse brain; when absent, abnormal axonal projection phenotypes are observed, suggesting an additional role for this Pcdh in axonal pathfinding. ${ }^{21}$ Additional studies report its involvement in synaptic elimination and apoptosis, thus suggesting a possible role for Pcdh10 in neurodegeneration..$^{22,23}$ Aberrations in proteins generally dealing with cell cycle control and apoptosis could affect neuronal plasticity and functioning. In the current study we investigated Pcdh10 expression in the most severely affected organ in the course of FAP disease, the peripheral nerve. With the use of tissues from different FAP mouse models, samples from human patients, and in vitro approaches, we found that Pcdh10 was consistently and significantly overexpressed in FAP peripheral nerves, triggered by the deposition of TTR toxic intermediate species. This phenotype was rescued in mice on preventive treatments, collectively implicating a role for Pcdh10 in FAP pathogenesis.

\section{Materials and Methods}

\section{Human Samples}

Formalin-fixed, paraffin-embedded sural nerve biopsy slides were obtained from FAP patients, asymptomatic carriers, and matched disease controls that were near-relatives of FAP patients who ultimately turned out not to have mutations in TTR. Biopsies from patients after liver transplantation were also used. This material was kindly provided by the Hospital Geral de Santo António, Porto, Portugal, and was obtained as part of the clinical diagnosis, before the current use of less invasive methods, as previously described. ${ }^{9}$ The material was previously characterized, after informed consent, for TTR and amyloid deposition by histologic analyses. ${ }^{10}$ In addition, human plasma samples from control subjects, asymptomatic carriers, and FAP patients in different stages of disease were also available after informed consent.

\section{FAP Mouse Models}

A transgenic mouse model for human $T T R \mathrm{~V} 30 \mathrm{M}$ in an endogenous Ttr null background (labeled as V30M), first described by Kohno et $\mathrm{al}^{24}$ and backcrossed for 10 generations into the Sv/129 background, was used. Eleven 6-month-old V30M and wild-type (WT) mice (Sv/129) were used for experiments with sciatic nerve injury; an additional six $\mathrm{V} 30 \mathrm{M}$ mice were used for naive nerve immunohistochemistry.

Another transgenic mouse line that carries the human TTR V30M mutation in the Sv/129 and endogenous Ttr null background but heterozygous for the heat shock factor 1 (Hsfl) (labeled as Hsf/V30M) was used in some experiments. ${ }^{25}$ Five mice aged 3 months, six mice aged 6 months, and six mice aged 22 months were analyzed. WT and WT mice heterozygous for $H s f l$ were used as controls. Mice were housed in a temperature-controlled room, maintained under a 12-hour light/dark period, with water and food ad libitum. A lethal injection of a premixed solution that contained ketamine plus medetomidine was used for animal sacrifice. Both sexes were used for all experiments shown. Mice were handled according to the European Community Council Directive (2010/63/EU), and experiments were approved by institutional and national regulations.

\section{Drug Design and Animal Treatment}

Hsf/V30M mice at 4.5 months of age were daily injected subcutaneously with $25 \mathrm{mg} / \mathrm{kg}$ anakinra (Kineret; Biovitrum Stockholm, Sweden) over 6 weeks $(n=7)$. Age-matched control untreated mice were injected with phosphatebuffered saline $(n=7)$. In this way, we were able to evaluate the protective role of anakinra on FAP cytotoxicity because mice have no TTR deposition in the peripheral nerve at the beginning of treatment, as assessed by semiquantitative immunohistochemistry. To be closest to the clinical human dose, and because it was previously described that mice respond to anakinra in a dose range of 1 to $100 \mathrm{mg} / \mathrm{kg},{ }^{26,27}$ we chose the dose of $25 \mathrm{mg} / \mathrm{kg}$, as previously described. ${ }^{28}$

Another group of Hsf/V30M mice aged 5 months $(n=6)$ was injected in the tail vein with human TTR siRNA, ${ }^{29}$ at a concentration of $1 \mathrm{mg} / \mathrm{kg}$ over 4 weeks. One intravenous injection was performed per week, and mice were euthanized 48 hours after the last injection. Untreated age-matched controls received vehicle intravenously only $(n=4)$. 
At the end of the therapeutic scheme, mice were sacrificed, and sciatic nerves were immediately dissected and fixed in $10 \%$ formalin for further processing.

\section{Sciatic Nerve Ligation}

Six-month-old WT and V30M mice were anesthetized with ketamine/medetomidine, and the left sciatic nerve was ligated at the mid-thigh level with 5.0 silk suture, as previously described. ${ }^{11,30}$ Buprenorphine was given subcutaneously, before surgery, and in the next 48 hours, twice a day. Skin was closed with the use of 5.0 surgical sutures, and mice were kept in a recovery room with infrared heating for 1 to 2 hours. After 7 days, mice were euthanized, and sciatic nerves were dissected free from surrounding tissues and collected into $10 \%$ formalin ( $n=5$ per group) or RNA ( $n=6$ per group) later for posterior freezing at $-80^{\circ} \mathrm{C}$.

\section{Microarray Hybridization}

For microarray analysis, mRNA from WT and V30M injured sciatic nerves was extracted 7 days after lesion $(n=2$ per strain), using the Lipid Tissue Mini Kit (Qiagen, Hilden, Germany). mRNA integrity was assessed with Experion RNA StdSens Analysis Kit (Bio-Rad, Hercules, CA); samples used had a similar RNA quality indicator. Equal amounts of mRNA extract (200 ng) from each replicate were amplified and labeled with cyanine 3 with the use of the Low Input Quick Amp Labeling kit (Agilent Technologies, Santa Clara, CA). In vitro synthesized transcripts (Spike-in kit), in predetermined ratios, were used to monitor microarray workflow for linearity, sensitivity, and accuracy. Hybridizations were performed at $65^{\circ} \mathrm{C}$ for 17 hours, according to the manufacturer's instructions for One-Color MicroarrayBased Gene Expression Analysis (Agilent Technologies), using mouse whole-genome $4 \times 44 \mathrm{~K}$ version 2 Microarray slides. After washing, microarray slides were immediately scanned in the Agilent G2565AB microarray scanner, and fluorescence quantification was performed with Agilent Feature Extraction software version 10.5.1.1 (Agilent Techonologies), according to the protocol recommendations (GE1_105_Dec08). The signal intensity was aligned by centering the median of the signal distribution with the use of the Biometric Research Branch-ArrayTools version 3.4.0, taking median array intensity as reference.

\section{Microarray Data Analysis}

The MultiExperiment Viewer version 4.3 (Dana-Farber Cancer Institute, Boston, MA) was applied for statistical analysis of the data. Differentially expressed transcripts between the two conditions were filtered with the use of the Class Comparison tool, by performing a Student's $t$-test, assuming equal variances with a $P$ value cutoff of 0.05 . Of these, only differentially expressed genes with a fold-change $>1.5$ were considered and included in further analyses. For gene ontology evaluation, a list of differentially expressed genes between both mice strains were imported to Database for Annotation, Visualization, and Integrated Discovery. Experiments were performed and data were analyzed in the National DNA-Microarray Facility located at the University of Aveiro, Portugal.

\section{Real-Time PCR}

First-strand cDNA was synthesized with the SuperScript double-stranded cDNA Kit (Invitrogen, Carlsbad, CA), according to the manufacturers' instructions. Primers for target mouse genes were designed with the Beacon Designer software version 8 (Premier Biosoft International, Palo Alto, CA), and their sequences are displayed in Table 1. A standard calibration curve was performed by 10 -fold serial cDNA dilutions to assess primer efficiency.

Real-time quantitative PCR was conducted in duplicates with the use of the iQ Syber Green Super Mix (Bio-Rad), and reactions were analyzed in the iQ5 Multicolor RealTime PCR Detection System (Bio-Rad). Melting curves were performed to detect nonspecific amplification products. Five biological replicates were used per group. Differential expression was determined by the $2^{-\Delta \Delta \mathrm{C}_{\mathrm{T}}}$ method, using Gapdh as the housekeeping control gene.

\section{Semiquantitative Immunohistochemistry}

Three micron-thick paraffin sections were cut and deparaffinated in Histoclear (National Diagnostics, Atlanta, GA). After hydration, endogenous peroxidase activity was quenched with $10 \% \mathrm{H}_{2} \mathrm{O}_{2}$ in methanol, and sections were pretreated with blocking solution (10\% fetal bovine serum and $0.5 \%$ Triton $\mathrm{X}-100$ in phosphate-buffered saline) to avoid undesired background. Next, sections were incubated overnight at $4^{\circ} \mathrm{C}$ with primary antibodies, namely rabbit polyclonal anti-Pcdh10 (dilution 1:750; Antibodies Online, Atlanta, GA) and goat polyclonal anti-neuropilin-1 (Nrp-1; dilution 1:100; R\&D Systems, Minneapolis, MN). After washing in phosphate-buffered saline, sections were incubated for 45 minutes with biotinylated anti-rabbit or anti-goat IgG (Vector Laboratories, Burlingame, CA) at room temperature. The tissue was then washed and incubated for 30 minutes with the avidin-biotin peroxidase complex (ABC Elite; Vector Laboratories) and stained with $3,3^{\prime}$ diaminobenzidine. After a short rinse in tap water, sections were counterstained with hematoxylin for 20 seconds and intensely washed with tap water for 10 minutes. Sections were mounted with Entelan and coverslipped for microscope visualization. Images were acquired with Cell A 2.6, Build 1200 (Olympus Soft Imaging Solution, Munster, Germany), and semiquantitative analysis of the relative labeling intensity was performed with Image Pro-plus version 5.1 (Media Cybernetics, Rockville, MD). Quantification was blind (N.P.G. and D.M.), and each tissue was evaluated in five different areas with a $20 \times$ objective. The area occupied 
Table 1 Mouse Primer Sequences Used for Real-Time Quantitative PCR

\begin{tabular}{|c|c|c|}
\hline Gene & Forward & Reverse \\
\hline Pcdh10 & $5^{\prime}-$ AGACAGTGAACAGGGAGAC-3' & 5'-GGTTGCTGCGGTAATCTG-3' \\
\hline Nrp-1 & 5'-ACAGTGGCACAGGTGATGACTTC-3' & 5'-TGTCGGGAACTCTGATTGGATGGT-3' \\
\hline$H 28$ & 5'-ATGTGGAGGAGTATGATGAAGTTC-3' & $5^{\prime}$-AGAGCAGCAAAGACCAGAATATC- $3^{\prime}$ \\
\hline H6Oa & $5^{\prime}-\mathrm{CTCCAGTCACACCATAGGC-3^{ \prime }}$ & 5'-TGTCCATGTAGATTACGATAGTTG- $3^{\prime}$ \\
\hline Ccrl2 & 5'-АСАTСTGTTTATATCССTTGAGAG-3' & 5'-TTGTCCAGGTAGTCGTCTAAG-3' \\
\hline Cxcl10 & 5'-TTCTGCСTCATCCTGCTG-3' & 5'-AGACATCTCTGCTCATCATT-3' \\
\hline
\end{tabular}

by chromogen represents the amount of protein present, and the program selected all types of brown staining. Background is taken into consideration by the program in all analyzed groups, and results shown represent the area occupied by pixels that correspond to the immunohistochemical substrate's color that is normalized relative to the total area, with the corresponding SEM.

\section{Confocal Microscopy}

Double immunofluorescence was performed to colocalize Pcdh10 with Schwann cells, axons, Nrp-1, or F-actin. Briefly, sections were preincubated with blocking solution (10\% fetal bovine serum with $0.5 \%$ Triton X-100 in phosphate-buffered saline) at room temperature for 1 hour before the overnight incubation at $4{ }^{\circ} \mathrm{C}$ with the following primary antibodies: rabbit polyclonal anti-Pcdh10 (dilution 1:50; Antibodies Online), mouse monoclonal anti-S100 (dilution 1:20; Abcam, Cambridge, UK), mouse monoclonal anti- $\beta$ III-tubulin (dilution 1:1000; Promega, Madison, WI), goat polyclonal anti-Nrp-1 (dilution 1:50; R\&D Systems), or mouse anti-F-actin (dilution 1:25; Novus Biologicals, Littleton, $\mathrm{CO}$ ). In the day after, sections were incubated with the following secondary antibodies: goat anti-mouse Alexa Fluor 568, donkey anti-rabbit Alexa Fluor 488, or donkey anti-goat Alexa Fluor 568 for 2 hours at room temperature. Finally, sections were mounted with Vectashield with DAPI (Vector Laboratories) for nuclei visualization. Image stacks were obtained with a laser scanning Confocal Microscope Leica TCS SP5 II (Leica Microsystems, Wetzlar, Germany).

\section{Enzyme-Linked Immunosorbent Assay}

Levels of Pcdh10 in human plasma from disease controls $(n=5)$, asymptomatic carriers $(n=5)$, and FAP patients in different stages of disease (FAP 1, FAP 2, and FAP 3) $(n=5$ per group) were quantitatively determined by enzyme-linked immunosorbent assay, according to the manufacturer's instructions (MyBiosource, San Diego, CA).

\section{Preparation of TTR V30M Aggregates}

Recombinant TTR V30M was produced in an Escherichia coli BL21 system and was purified as previously described. ${ }^{31}$
Soluble TTR V30M was filtered through 0.2- $\mu \mathrm{m}$ Anotop syringe filters (Whatman, UK), and TTR aggregates were generated by incubating $2 \mathrm{mg} / \mathrm{mL}$ protein, with stirring, at room temperature for 7 days. ${ }^{32}$ TTR preparations were then tested by thioflavin $\mathrm{T}$ spectrofluorometric assay to search for their amyloidogenic potential. Dynamic light scattering at $25^{\circ} \mathrm{C}$ in a Malvern Zetasizer Nano ZS (Malvern, Worcestershire, UK) was also performed to confirm TTR pathogenic aggregation and specimen size. ${ }^{33}$

\section{Cell Culture}

RN22 cell line was cultured in Dulbecco's modified Eagle's medium (Lonza, Basel, Switzerland), supplemented with $10 \%$ fetal bovine serum, $2 \mathrm{mmol} / \mathrm{L}$ L-glutamine, and $100 \mathrm{U} /$ $\mathrm{mL}$ penicillin/streptomycin (all from Gibco, Waltham, MA). After monolayer propagation in $\mathrm{T}-75$ flasks at $37^{\circ} \mathrm{C}$ in a $5 \%$ $\mathrm{CO}_{2}$ humidified chamber, $5 \times 10^{5}$ cells were seeded in 6 -well plates and stimulated with TTR aggregates or soluble protein, both at $2.5 \mu \mathrm{mol} / \mathrm{L}$. Sixteen hours after stimulation, cell lysates were prepared in TRIzol (Invitrogen) and assayed for the expression of Pcdh10 by qPCR with the use of the following primers: rat Pcdh10 forward 5'-CGGCTGGAGAATACGACATT-3', reverse 5'-CGGCTTGGGTTTGGAGAT-3'; rat Gapdh forward 5'-ACCCATCACCATCTTC-3', reverse $5^{\prime}$-TAGACTCCACGACATACT-3'. Unstimulated cells were also used as controls.

\section{Statistical Analysis}

Results are presented as means \pm SEM. Statistical significance was assessed by one-way analysis of variance, followed by Bonferroni's posttest or by Student's $t$-test. Statistical analysis was performed with GraphPad Prism 5 (GraphPad Software, Inc., La Jolla, CA) and set up for $P<0.05$.

\section{Results}

Differential Expression of Genes Coding for Cell Adhesion, Immunity, and Defense in V30M Mice after Sciatic Nerve Injury

The most classic animal model for FAP is a mouse strain that has the human TTR V30M variant but lacks the 
endogenous mouse Ttr gene. These mice contained several copies of the human gene, and TTR deposition resembled that of human FAP patients in the gastrointestinal tract and skin, but still without deposition occurring in PNS or autonomic NS. ${ }^{24}$ It was previously found that an inflammatory stimulus in the peripheral nerve of these mice, such as sciatic nerve ligation, was able to trigger and preceded TTR V30M deposition, contributing to the positive feedback loop of toxicity and FAP progression. ${ }^{11}$ To investigate the molecular mechanisms underlying this phenomenon we performed a whole-mouse genome Agilent microarray analysis of injured V30M nerves compared with those from WT mice. The profiles identified 521 genes whose expression was up-regulated in damaged V30M nerves, compared with those from WT mice, and 223 transcripts downregulated $>1.5$-fold with $P<0.05$ (https://www.ebi.ac.uk/ arrayexpress/help/accession_codes.html, array accession number E-MTAB-4525). The transcriptional gene expression found that distinct signaling pathways were differentially up-regulated by the presence of mutated TTR V30M in the peripheral nerve. In this way, analysis of gene ontology with Database for Annotation, Visualization, and Integrated Discovery Bioinformatics Resources tool revealed that up-regulated genes belong to a diverse set of categories, including cell adhesion, developmental processes, regulation of mRNA transcription, extracellular transport, and cell communication (Figure 1A and Table 2). In contrast, the pattern of down-regulated genes related with the presence of TTR V30M was mostly associated with immunity and defense, although categories such as protein phosphorylation, phospholipid metabolism, cell motility, proliferation, and differentiation were also poorly regulated in injured nerves of V30M mice (Figure 1B). We then selected the functional gene classes with potential relevance to FAP pathophysiology. According to the microarray data, genes coding for several cytokines, chemokines, and immune mediators were differentially regulated by the presence of V30M (Supplemental Table S1). From those, Tolllike receptor 1 and chemokine (C-X-C motif) ligand 2 and 3 were previously found down-regulated in V30M injured nerves compared with WT by real-time PCR analysis, thus corroborating microarray data. ${ }^{11}$ Histocompatibility 28, histocompatibility 60a, and chemokine (C-C motif) receptor-like 2 were also validated with real-time quantitative PCR. In contrast, not validated genes include Tlr3, Cxcl10, or Cxcll1 (data not shown). Overall, the real-time quantitative PCR analysis confirmed nerve injury-induced repression of immunity and defense-associated genes in V30M mice. As such, our results pointed toward an impaired activation of Schwann cell transcriptional immune program after nerve lesion, possibly resulting from the upregulated synthesis of TTR V30M variant, ${ }^{11}$ also found in this microarray with a fold change of 4.29 (Table 2). Additional genes significantly enriched in injured V30M nerves belong to the cell adhesion category, mediating cellto-cell and cell-to-matrix interactions (Figure 1A). From all

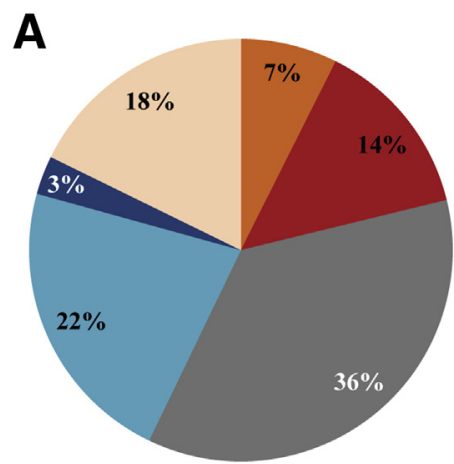

- Cell adhesion mediated signaling

- Cell adhesion

- Developmental processes

mRNA transcription regulation

- Extracellular transport and import

Cell communication

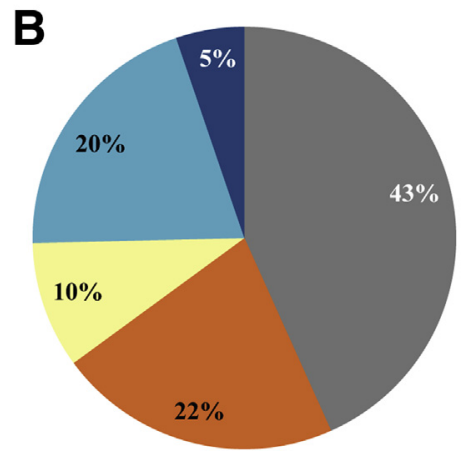

Immunity and defense

- Protein phosphorylation

Cell motility

Cell proliferation and differentiation

- Phospholipid metabolism

Figure 1 Genome expression patterns of injured V30M nerves compared with those from WT mice. Pie charts demonstrate transcripts up-regulated (A) and down-regulated (B) in damaged V30M nerves relative to control. Gene ontology analyses included genes that had $P<0.05$, a fold change $>1.5$, and was performed with the use of DAVID Bioinformatics Resources. Mice were 6 months of age. DAVID, Database for Annotation, Visualization, and Integrated Discovery; V30M, replacement of a methionine for a valine at codon 30; WT, wild-type.

of the up-regulated molecules, particular interest relied on Pcdh10 because of the higher fold change $(277 \times)$, lower $P$ value, and its possible association with $\mathrm{Nrpl}$, a gene also found up-regulated in this microarray (Table 2). Real-time

Table 2 Genes Found Up-Regulated in V30M Injured Sciatic Nerves Compared with Damaged Nerves from WT Mice

\begin{tabular}{llcl}
\hline Gene name & Symbol & Fold change & $P$ \\
\hline Protocadherin-10 & Pcdh10 & 277.13 & 0.0084 \\
Collagen, type XXVII, $\alpha$ 1 & Col27a1 & 33.92 & 0.023 \\
$\begin{array}{l}\text { Thrombospondin, type I, } \\
\quad \text { domain-containing }\end{array}$ & Thsd7b & 5.81 & 0.039 \\
$\quad$ protein 7B & & & \\
$\begin{array}{l}\text { Apolipoprotein C-II } \\
\text { Transthyretin }\end{array}$ & Apoc2 & 5.14 & 0.024 \\
$\begin{array}{l}\text { Neuropilin-1 } \\
\text { CAMP responsive element }\end{array}$ & TrR & 4.29 & 0.027 \\
$\quad$ Creb3 & 3.24 & 0.02 \\
$\begin{array}{l}\text { Actinding protein 3 } \beta \text {-like 2 } \\
\text { CCAAT/enhancer binding } \\
\quad \text { protein (C/EBP), } \alpha\end{array}$ & Cebpa & 2.56 & 0.043 \\
\hline
\end{tabular}

Genes were considered up-regulated with fold-change $>1.5$ after class comparison, assuming significances $P<0.05$.

V30M, replacement of a methionine for a valine at codon 30; WT, wildtype. 
PCR and immunohistochemical analysis denoted a significant up-regulation of Pcdh10 gene expression and protein levels in injured V30M sciatic nerve, compared with injured WT mice (Figure 2, A and B), thus validating array data. For Nrp-1, only a trend for higher RNA message in injured V30M nerves was detected with realtime quantitative PCR (Figure 2C); however, protein levels were found highly increased in V30M mice nerves after damage, compared with injured nerves from WT mice (Figure 2D). Collectively, these observations provided evidence for the hypothesis that Pcdh10 and Nrp-1 might be activated consequently to TTR V30M nerve deposition and consequent neurodegeneration on nerve injury, because they were not observed in injured WT mice.

Pcdh10 Is Expressed in Axons and Schwann Cells from V30M Injured Peripheral Nerve and Colocalize with the Axon Guidance Molecules Nrp-1 and F-actin

Pcdh10 immunopositive staining in V30M peripheral injured nerve was confirmed with double immunofluorescence labeling between this molecule and BIII-tubulin or S100, indicating Pcdh10 expression by axons and Schwann cells (Figure 3A).

In addition, cellular localization studies with confocal microscopy denoted colocalization of Pcdh10 with Nrp-1 and $\mathrm{F}$-actin in the proximal stump of $\mathrm{V} 30 \mathrm{M}$ injured sciatic nerves (Figure 3B), indicating that Pcdh10 might be capable of interacting with these axon guidance molecules important for growth cone formation during development.
Overexpression of Pcdh10 by Schwann Cells and Axons of the Peripheral Nerve Correlates with the Presence of TTR V30M Mutation and Nonfibrillar Deposition

In light of the above-mentioned data, we investigated whether alterations in the transcriptional machinery in an FAP peripheral nerve injury model may be translated to the naive situation. To test this hypothesis, we used the following two FAP mouse models: the one mentioned above (the V30M mice) and another one carrying the TTR V30M mutation in a heterozygous Hsfl background (Hsf/ V30M). The impaired chaperone response led to relatively early TTR gastrointestinal deposits and unique protein deposition in the PNS and autonomic NS, when mice achieved 6 months of age. Moreover, the Hsf/V30M model displayed signs of inflammatory and oxidative stress closely replicating patient nerve pathologic disorders. ${ }^{25}$

Thus, we started by analyzing nerve Pcdh 10 protein levels in different stages of disease by using Hsf/V30M FAP transgenic mice at 3, 6, and 22 months of age, aiming at associating Pcdh10 expression with nonfibrillar TTR deposition in nerve tissue. Through histologic examination we could perceive that nerves from 3-month-old mice presented low Pcdh10-positive immunostaining (Supplemental Figure S1A), corresponding to a stage in which TTR nonfibrillar deposits were still absent from the PNS. ${ }^{25}$ A remarkable increase in Pcdh10 protein levels was noted in mice aged between 3 and 6 months (Supplemental Figure S1A), correlating with the beginning of TTR aggregation in peripheral nerve. ${ }^{25} \mathrm{~A}$ trend for increased expression, although not statistically significant, was found in mice between 6 and 22 months of age (Supplemental Figure S1A).
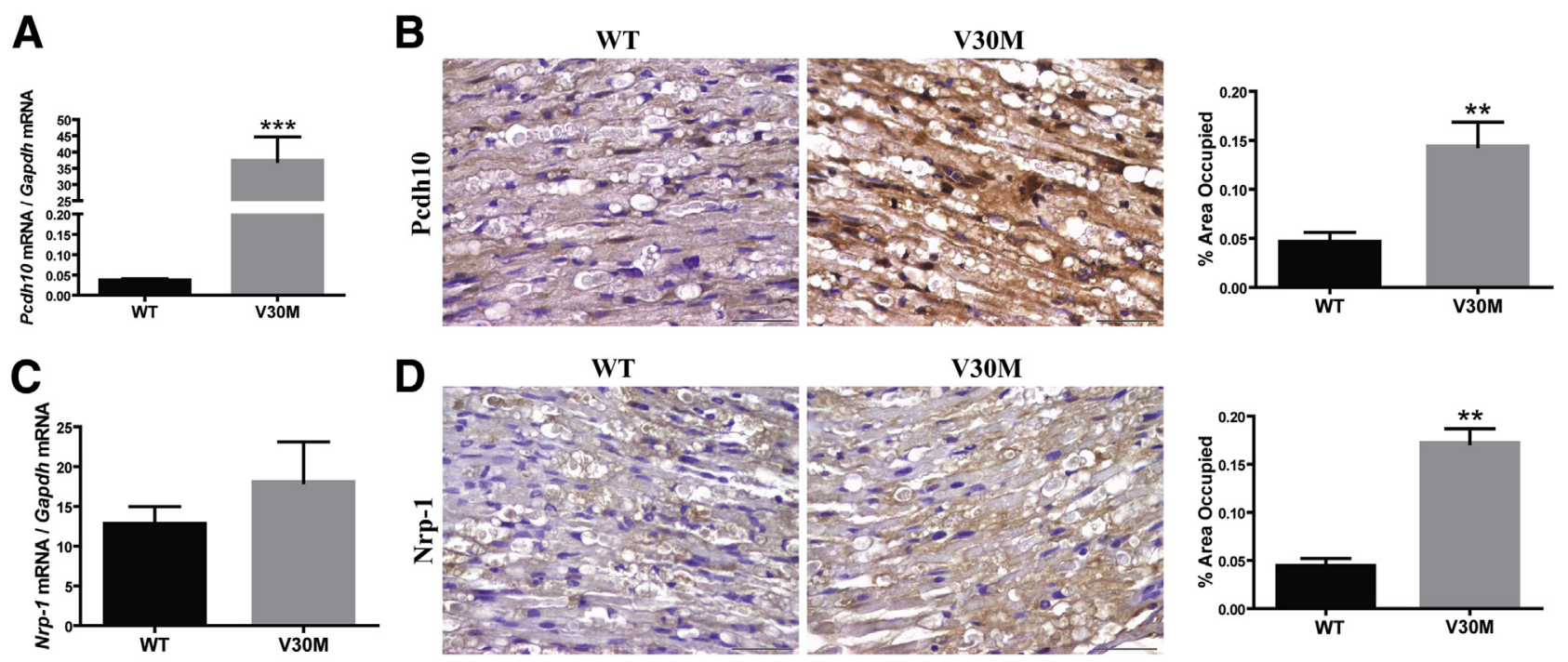

Figure 2 Overexpression of Pcdh10 and Nrp-1 in injured V30M nerve. A: Histogram represents Pcdh10 mRNA levels in the sciatic nerve of both mice strains aged 6 months, 7 days after injury, normalized against Gapdh. B: Representative semiquantitative immunohistochemistry against Pcdh10 protein levels in WT and V30M injured nerves. Chart represents quantification of immunohistochemical images. C: Nrp-1 expression in damaged V30M nerves compared with WT. Histogram represents relative gene quantification, normalized against Gapdh mRNA. D: Histologic analysis of Nrp-1 after peripheral nerve injury. Data represent relative quantification of substrate positive immunoreactivity, related to total tissue area. Data are expressed as means \pm SEM. ${ }^{* *} P<0.01, * * * P<0.001$. Scale bars $=50 \mu \mathrm{m}$. Nrp-1, neuropilin-1; Pcdh, protocadherin; V30M, replacement of a methionine for a valine at codon 30; WT, wild-type. 
A
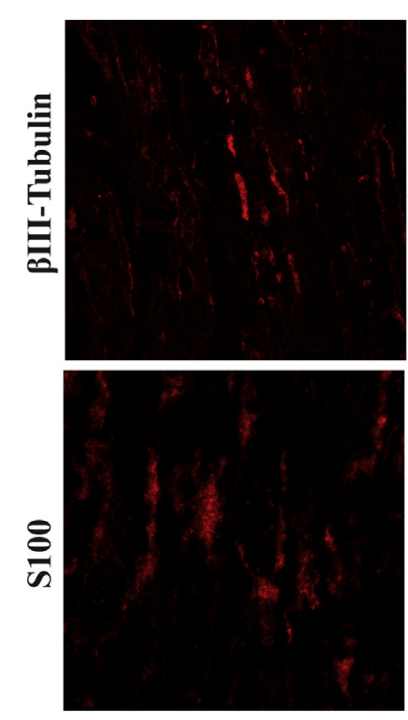

B
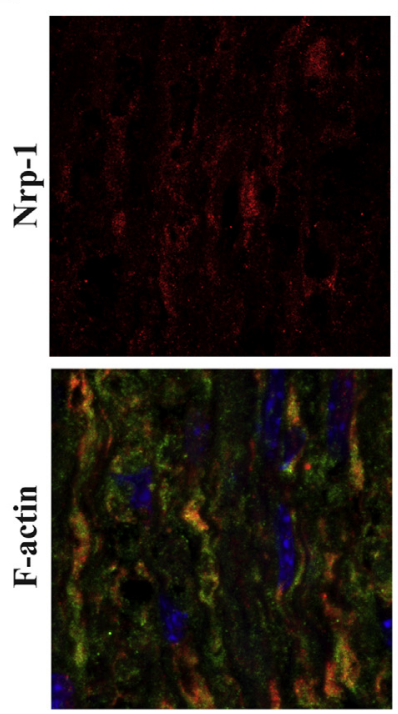

Pedh10
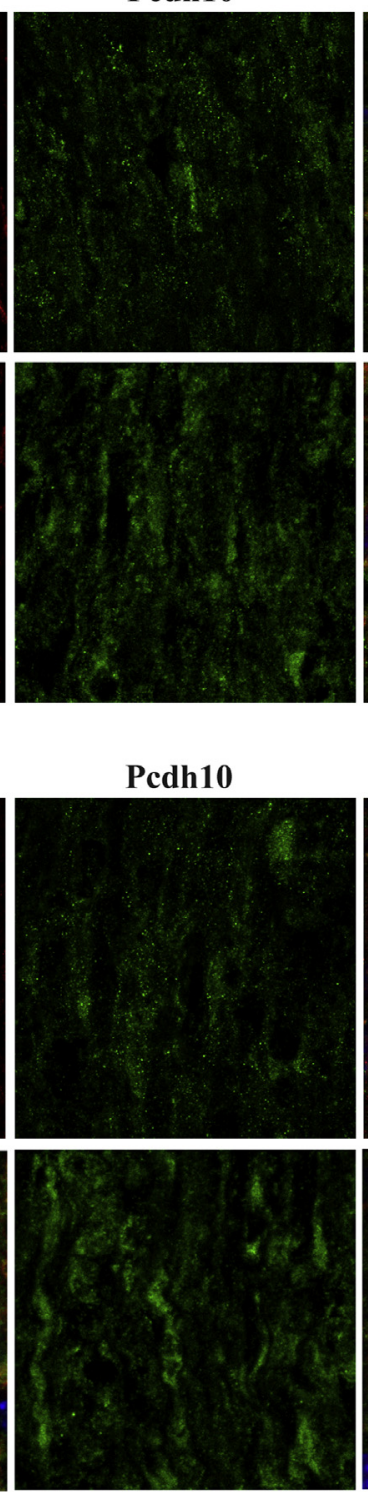

Merge

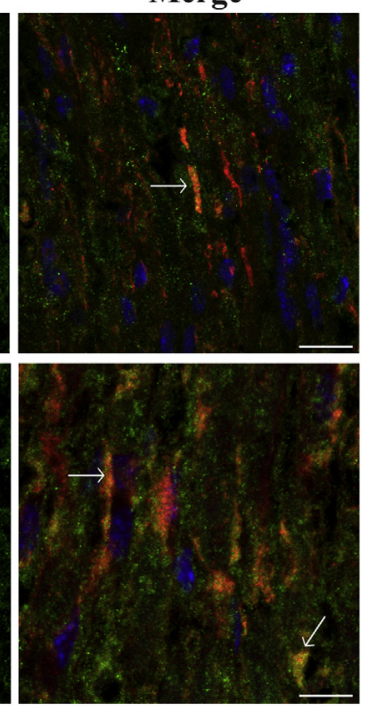

Merge
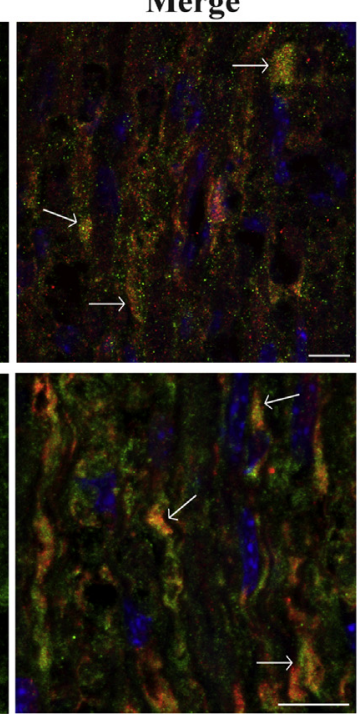

Figure 3 Pcdh10 localizes in axons and Schwann cells and is associated with axon guidance cues, after peripheral nerve lesion. A: Confocal microscopy of V30M injured peripheral nerve, from 6-month-old mice, indicated immunopositive staining of Pcdh10 in axons and Schwann cells, as highlighted with colocalization with $\beta$ III-tubulin and S100 (arrows). B: Immunofluorescence double staining indicated colocalization of Pcdh10 with Nrp-1or F-actin in the proximal stump of V30M injured sciatic nerves (arrows). Scale bars $=10 \mu \mathrm{m}$. Nrp-1, neuropilin-1; Pcdh, protocadherin; V30M, replacement of a methionine for a valine at codon 30 .
Therefore, at this point, it seems that Pcdh10 overexpression correlated with nerve TTR deposition. Moreover, we found that Pcdh10 gene and protein up-regulation in mice with nerve TTR V30M deposition was independent of $\mathrm{Hsfl}$ deficiency, because no difference was noted between $H s f l$ heterozygous WT (Hsf/WT) or WT mice (Figure 4, A and B). Interestingly, histologic examination denoted a similar pattern of Pcdh10 overexpression in the V30M transgenic mouse model missing nerve TTR load (Figure 4B), suggesting that, in addition to TTR nonfibrillar deposition, the presence of the V30M mutation in TTR gene was sufficient to induce alterations in peripheral signaling and translational machinery, as previously noticed. ${ }^{34}$ Because Hsf/V30M mice closer resemble human pathology, the subsequent studies were performed with this mouse strain.

Immunofluorescent double labeling confirmed Pcdh10 cellular localization in both Schwann cells and axons of
FAP naive nerve (Figure 4C), similar to what was found in the injury situation.

Staining visualized by confocal microscopy revealed that Pcdh10 is frequently co-expressed with Nrp-1 and F-actin in naive peripheral nerve from Hsf/V30M transgenic mice at 6 months of age (Supplemental Figure S1B). Given that TTR nonfibrillar deposition in the PNS of this FAP mouse model increases with age to contribute for the loss of unmyelinated axons, ${ }^{25}$ it is reasonable to suggest that Pcdh10 association with axon guidance molecules might account for nerve growth cone formation; therefore, we next questioned about the FAP nerve protein levels of Nrp-1, a protein found on the cell surface of growth cones. ${ }^{35}$ Increased Nrp-1 in Hsf/ V30M peripheral nerve started about 6 months of age and reached maximum levels when mice were 22 months old (Supplemental Figure S1C), thus correlating with TTR nonfibrillar deposition and overexpression of Pcdh10. 
A

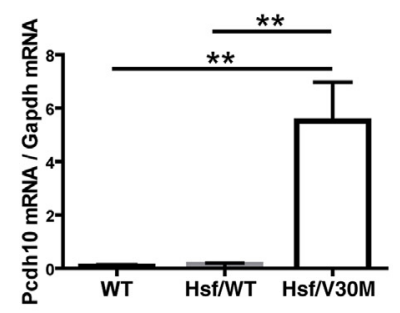

B

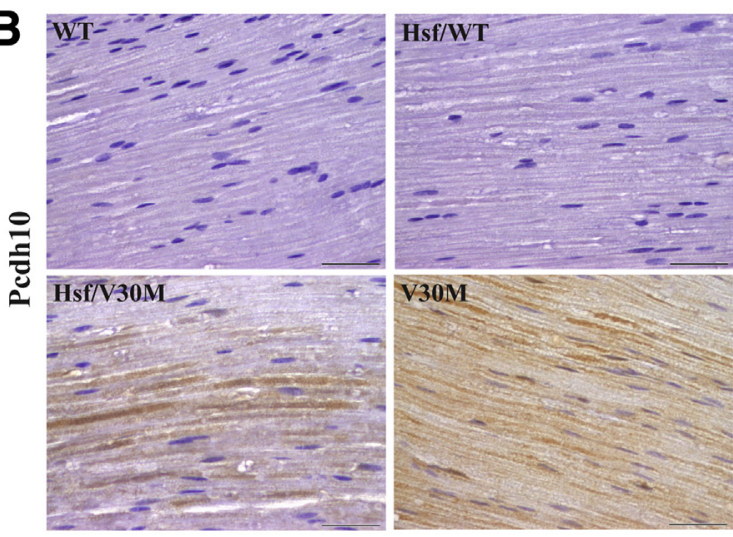

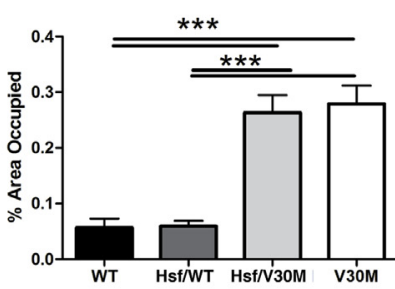

C

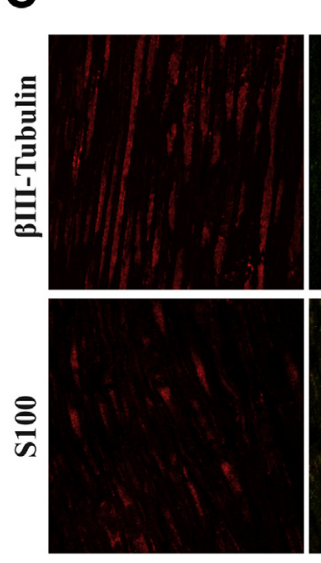

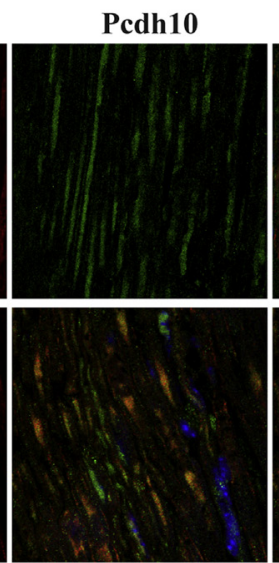

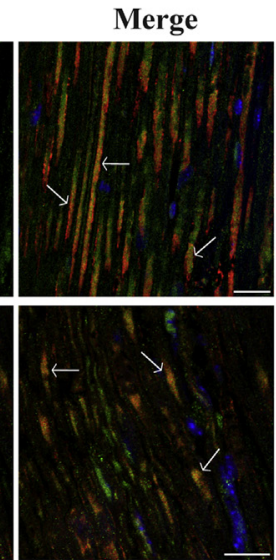

Figure 4 0verexpression of Pcdh10 in a naïve FAP mouse model. A: Up-regulation of Pcdh10 in the sciatic nerve of Hsf/V30M mice evaluated by real-time quantitative PCR, compared with Hsf/WT and WT mice. Normalization was performed against Gapdh mRNA. B: Pcdh10 protein levels in the peripheral nerve assessed by semiquantitative immunohistochemistry, with respective semiquantification, demonstrating increased protein levels in FAP transgenic mouse models. C: Double immunofluorescence found Pcdh10-positive axon fibers (top row) and Schwann cells (bottom row) in a naive FAP mouse model. Arrows point to regions of colocalization between markers. All analyzed mice were 6 months old. Data are expressed as means \pm SEM. ${ }^{* *} P<0.01,{ }^{* * *} P<0.001$. Scale bars: $50 \mu \mathrm{m}$ (B); $20 \mu \mathrm{m}$ (C, top row); $15 \mu \mathrm{m}$ (C, bottom row). FAP, familial amyloidotic polyneuropathy; Hsf, heat shock factor 1 ; Pcdh, protocadherin; V30M, replacement of a methionine for a valine at codon 30; WT, wild-type.

Increased Pcdh10 Expression by Glial Cells Is Induced by TTR Aggregated Species

To examine if intracellular production of Pcdh10 was induced by the extracellular stimulation with TTR-aggregated toxic species, TTR V30M aggregates were originated by stirring for further incubation in a Schwannoma cell line. TTR aggregates had a medium particle size of approximately $1000 \mathrm{~nm}$, as assessed by dynamic light scattering, and a potent amyloidogenic potential, compared with soluble protein or blank control, highlighted with thioflavin $\mathrm{T}$ (Supplemental Figure S2A). After overnight incubation, we observed that aggregated TTR increased Pcdh10 mRNA (Supplemental Figure S2B) compared with nontreated cells or cells incubated with soluble TTR.

\section{Reduced Pcdh10 Nerve Expression in Hsf/V30M Mice Treated with Anakinra or TTR siRNA}

It was previously found that treatment of $\mathrm{Hsf} / \mathrm{V} 30 \mathrm{M}$ mice with anakinra or TTR siRNA prevents TTR nonfibrillar deposition in the peripheral nerve either by decreasing inflammation or silencing TTR liver synthesis, respectively. ${ }^{11,28}$ To examine if Pcdh10 levels followed the TTR behavior we subsequently undertook histologic analyses of treated nerves compared with the respective controls and

found Pcdh10 protein expression highly reduced in peripheral nerves on both therapeutic approaches (Figure 5).

\section{Pcdh10 Levels Correlate with FAP Disease}

Prompted by the results obtained in vivo and in vitro, we finally tested the expression of Pcdh10 in human samples. Immunohistochemical analysis of sural nerve biopsies from FAP patients versus asymptomatic V30M carriers and normal control subjects found evident alterations in Pcdh10 protein levels in advanced stages of disease, when massive nonfibrillar TTR and amyloid deposits were already present, followed by substantial nerve degeneration ${ }^{9}$ (Figure 6A). Moreover, by histologic examination, increased expression of Pcdh10 was predominantly detected in axons (Figure 6A). In addition, when looking to Pcdh10 after liver transplantation as a form of FAP treatment, we observed that this procedure did not alter Pcdh10 protein levels in sural nerve biopsies (Supplemental Figure S3), possibly reflecting that liver transplantation does not change TTR that is already aggregated in the periphery.

Subsequently, we addressed Pcdh10 protein levels in plasma from controls, asymptomatic subjects, and FAP patients in different stages of disease. From the density of nerve fibers, a scoring system had been used for the classification of patient material and stage of disease. In this 

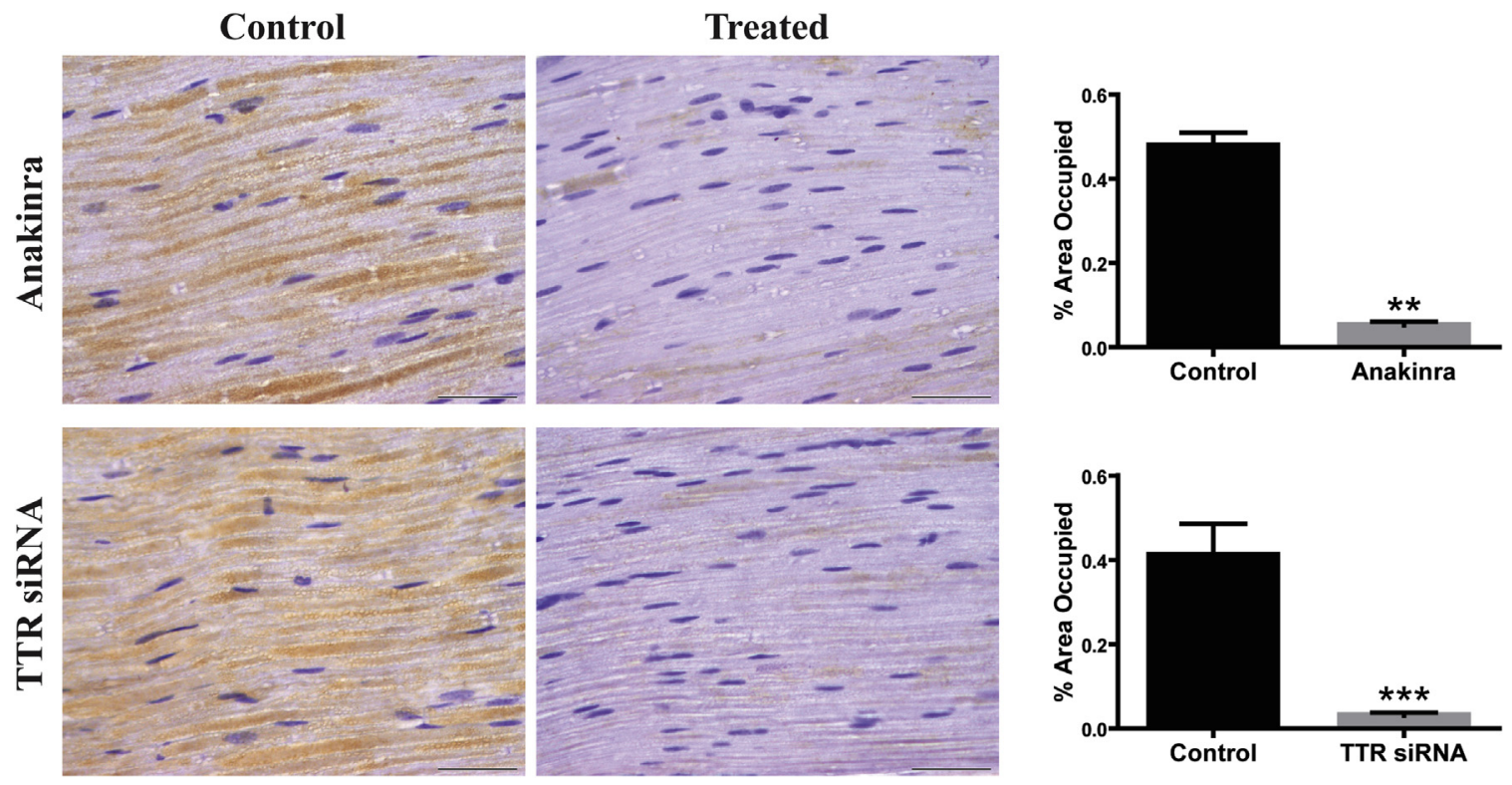

Figure 5 Pcdh10 down-regulation after treatment with drugs that inhibit TTR nerve deposition, such as anakinra or TTR siRNA. Peripheral nerve images showing decreased Pcdh10 immunostaining in sciatic nerves from 6-month-old Hsf/V30M mice treated with anakinra or TTR siRNA, as related to vehicleinjected mice. Data are expressed as means \pm SEM. ${ }^{* *} P<0.01,{ }^{* *} P<0.001$. Scale bars $=50 \mu \mathrm{m}$. Hsf, heat shock factor 1; Pcdh, protocadherin; TTR, transthyretin; V30M, replacement of a methionine for a valine at codon 30.

way, FAP 1 patients present a discrete decrease in nerve fiber density and fibrillar TTR deposition start to appear, whereas FAP 2 and 3 have evident or severe fiber reduction, respectively, with extensive amyloid deposition. ${ }^{9}$ Thus, plasma samples from patients accordingly classified with this score system were analyzed by enzyme-linked immunosorbent assay, and results displayed a significant increase in Pcdh10 protein levels with neuropathy progression (Figure 6B). All together, these results suggested that Pcdh10 might be a novel disease biomarker for FAP pathologic process.

\section{Discussion}

In the present report we described for the first time expression of Pcdh10 in the adult peripheral nerve in association with a peripheral neuropathy. This adhesion molecule was significantly up-regulated in Schwann cells and axons of FAP tissue and might contribute to the disease pathologic profile. More interestingly, Pcdh10 mRNA induction by TTR aggregates and protein level downregulation with treatments positively acting over TTR deposition and toxicity suggest that this molecule could be an interesting novel therapeutic target in this neurodegenerative disorder.

Accumulating evidence finds that inflammation and extracellular matrix remodeling contribute to the neurodegenerative process in FAP. ${ }^{10,28,36}$ The proposed mechanism underlying these observations encompasses binding of TTR species to receptor for advanced glycation end products with activation of extracellular signal-regulated kinases 1 and 2, $\mathrm{NF}-\mathrm{KB}$ translocation, and consequent transcription of proinflammatory mediators such as tumor necrosis factor- $\alpha$, IL-1 $\beta$, and macrophage-colony stimulating factor. ${ }^{34,37}$ However, cytokine-driven neuroinflammation is closely related with dynamic extracellular matrix turnover, ultimately altering cell-cell or cell-matrix communication. Cadherins are glycoproteins that mediate mechanical adhesion between cells, also crucial for tissue morphogenesis, polarity, cell movement, and synaptic connections. ${ }^{38}$ They were recently linked to central degenerative neurologic disorders such as Alzheimer or Parkinson disease, with N-cadherin promoting synaptic stability or dopaminergic neuroprotection. ${ }^{39,40}$

Additional members of the cadherin superfamily of calcium-dependent cell-adhesion molecules, highly expressed in the developing nervous system, are Pcdhs. ${ }^{41}$ Their functions and molecular mechanisms are largely unknown, but studies that focus on nonclustered 82 subfamily members indicate that Pcdhs are important for growth of striatal axons and patterning of corticothalamic projections during embryonic development. ${ }^{21,42}$ Moreover, genome-wide association studies have implicated Pcdh10 in autism, possibly relating with synaptic pruning, ${ }^{18,22}$ consistent with a role for this molecule about central nervous system biology.

Here, Pcdh10 was identified by microarrays with a noteworthy higher fold of expression in FAP injured peripheral nerves, when comparing with those from WT mice. Molecules that are up-regulated in the vicinity of nerve injury are likely to be involved in the regulation of axonal regrowth, suggesting that increased expression of Pcdh10 could be induced to support nerve regeneration. This theory is indirectly supported by experimental evidences to indicate that Pcdh10 is able to promote axon guidance ${ }^{21}$; however, it 
A

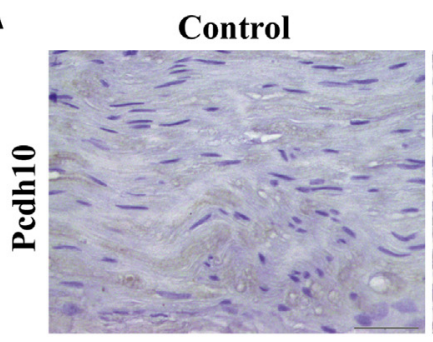

Asymptomatic

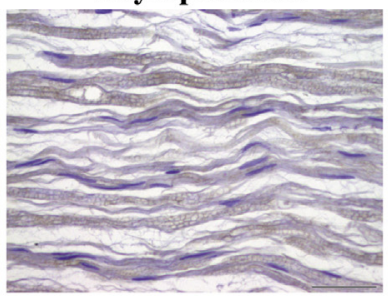

FAP

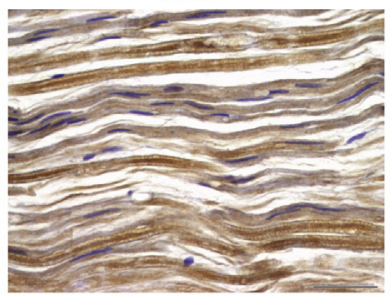

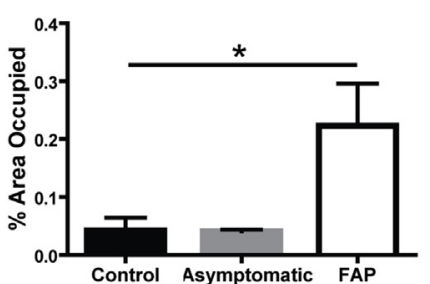

B

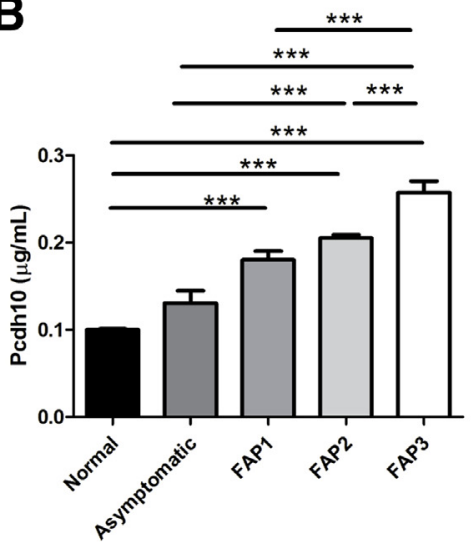

Figure 6 Pcdh10 misexpression in sural nerve biopsies from FAP patients. A: Pcdh10 immunohistochemical staining in human sural nerve found increased expression of this adhesion molecule with FAP progression. B: Pcdh10 plasma levels, assessed by enzyme-linked immunosorbent assay, in normal control subjects, asymptomatic carriers, and FAP patients in different stages of disease. Data were analyzed with the use of one-way analysis of variance. Data are expressed as means \pm SEM. $n=4$ disease controls (A); $n=3$ asymptomatic carriers (A), $n=3$ FAP patient samples (A); $n=5$ per group (B). ${ }^{*} P<0.05,{ }^{*} * P<0.001$. Scale bars $=50 \mu \mathrm{m}$. FAP, familial amyloidotic polyneuropathy; Pcdh, protocadherin. is possible that, taking the chronic course of disease, the higher Pcdh10 content could represent a mechanical barrier and thus hamper the regenerative process. In fact, it was recently reported that Pcdh10 repressed the expression of Akt, increasing the levels of glycogen synthase kinase $3 \beta$ in multiple myeloma. ${ }^{43}$ Overactivation of glycogen synthase kinase $3 \beta$ might lead to poor nerve regeneration, ${ }^{44}$ and, notably, compromised peripheral nerve regeneration and neurite outgrowth was found in vivo and in vitro in the context of FAP. ${ }^{11,28,45}$

An imbalanced Schwann cell activation with compromised production of chemoattractant cues and neurotrophins, as previously reported ${ }^{10,11}$ and highlighted in this microarray, could also contribute to lower chemotaxis, neurodegeneration, and FAP progression. It is known that adhesion molecules interact with membrane receptors, matrix proteins, and signaling cues that might in turn control synaptic strength. For instance, Pcdh10 and Pcdh17 are able to interact with the WAVE complex ${ }^{13,46,47}$ which in turn is a key regulator of actin cytoskeleton. ${ }^{48}$ F-actin dynamics plays many roles during synaptogenesis and axon branching 49,50 and is also important for the regulation of growth cone extension. With confocal microscopy, we investigated the aspects of Pcdh10 and F-actin accumulation at cell-cell contacts and demonstrate that associations between both proteins were present in FAP peripheral nerves, both after injury and in the naive situation. Colocalization of F-actin to Pcdh10- positive sites suggests that behavior of both molecules was tightly linked and that Pcdh10 may influence subcellular actin cytoskeletal organization. Interestingly, it was found that binding of amyloid- $\beta$ to integrin receptors on the neuronal surface activates F-actin signal transduction pathway, ultimately leading to soma degradation, ${ }^{51}$ indicating a role for microtubule dynamics in neurodegeneration. Collectively, these evidences point toward an important role for cytoskeleton remodeling in the pathogenesis of neurodegenerative diseases and suggests that Pcdh10 may be involved in this process, in the context of FAP.

Another interesting molecule highlighted by this microarray was Nrp-1. Protein analysis validated array data and found up-regulation of Nrp-1 in FAP peripheral nerve. This is particularly relevant because Nrp receptors and their ligands are known to play prominent roles in axonal regeneration, fasciculation, or angiogenesis. ${ }^{52,53}$ Moreover, Nrp-1 was found to interact with Pcdh10, mainly regulating the selective axon-axon interactions. ${ }^{54}$ In the current work, several Pcdh10-positive fibers and cells expressed Nrp-1, suggesting signaling interaction between both molecules in FAP. Interestingly, Nrp-1 was found reduced in diabetic patients, and a relation between this molecule and cytoskeleton organization of glomerular vascular endothelial cells was reported.$^{55}$ In FAP, because nerve regeneration is compromised, ${ }^{10,11,45}$ Nrp-1 might be up-regulated by nerve cells as a compensatory mechanism in an attempt to promote regeneration.

Programed cell death is crucial for normal neural development and physiologic aging, playing a key role in the construction of an efficient neuronal network. However, under pathologic conditions, it is also co-responsible for the loss of neurons associated with neurodegenerative disorders. ${ }^{56}$ Activation of apoptotic signaling platforms in FAP were found by evidence of DNA fragmentation, increased levels of the executioner caspase- $3,{ }^{10} \mathrm{Bax}$, caspase- 8 , and 
overactivation of Fas death receptor, ${ }^{57}$ all linked to the presence of TTR nonfibrillar aggregates, ultimately leading to neurodegeneration. Consistent with this, Pcdh10 was found to be a transcriptional target of p53 and seems to play a role in inhibiting cancer cell motility and migration by promoting cell apoptosis. ${ }^{23,58}$ Therefore, it is also reasonable to suggest that increased levels of Pcdh10 in FAP could contribute to cell death, dysregulating tissue homeostasis, and axon-glia interactions.

Overall, in this work we investigated ontologic classes that might be dysregulated consequently to increased TTR synthesis by the Schwann cells and nerve deposition of TTR intermediate species. Pcdh10 and Nrp-1 are molecules that participate in the formation of neuronal networks and were identified significantly up-regulated in FAP samples, thus probably implicated in the pathogenesis of this hereditary peripheral polyneuropathy. Furthermore, data shed light on the importance of cytoskeleton rearrangements in the course of peripheral neuropathies and suggests Nrp-1 and F-actin as Pcdh10-interacting partners in FAP neurodegenerative disease. However, the particular role of Pcdh10 in the progress of disease remains to be answered. It is possible that Pcdh10 might also be up-regulated in other peripheral neuropathies. Further studies should be conducted to address these questions.

Novel insights into FAP pathophysiology are of major importance for the development of new therapeutic strategies. Misexpression of Pcdh10 in FAP peripheral nerve might influence axonal phenotypes and signaling complexes, being thus a promising target for therapy. In addition, data with patient samples highlight the potential for this molecule as a novel biomarker for FAP progression.

\section{Acknowledgments}

We thank Dr. Laura Carreto (Aveiro University) for help with microarray analysis, and Paula Gonçalves and Paul Moreira (IBMC) for paraffin tissue processing and protein production, respectively.

N.P.G. and D.M. acquired, analyzed, and interpreted data and wrote the manuscript; M.J.S. wrote and revised the manuscript, and is the guarantor of this work and, as such, had full access to all of the data in the study and takes responsibility for the integrity of the data and the accuracy of the data analysis.

\section{Supplemental Data}

Supplemental material for this article can be found at http://dx.doi.org/10.1016/j.ajpath.2016.02.020.

\section{References}

1. Westermark P: The pathogenesis of amyloidosis: understanding general principles. Am J Pathol 1998, 152:1125-1127
2. Benson MD, Kincaid JC: The molecular biology and clinical features of amyloid neuropathy. Muscle Nerve 2007, 36:411-423

3. Saraiva MJ, Birken S, Costa PP, Goodman DS: Amyloid fibril protein in familial amyloidotic polyneuropathy, Portuguese type. Definition of molecular abnormality in transthyretin (prealbumin). J Clin Invest 1984, 74:104-119

4. Andrade C: A peculiar form of peripheral neuropathy; familiar atypical generalized amyloidosis with special involvement of the peripheral nerves. Brain 1952, 75:408-427

5. Ando Y: Liver transplantation and new therapeutic approaches for familial amyloidotic polyneuropathy (FAP). Med Mol Morphol 2005, 38:142-154

6. Planté-Bordeneuve V, Said G: Familial amyloid polyneuropathy. Lancet Neurol 2011, 10:1086-1097

7. Saraiva MJ, Magalhaes J, Ferreira N, Almeida MR: Transthyretin deposition in familial amyloidotic polyneuropathy. Curr Med Chem 2012, 19:2304-2311

8. Misu Ki, Hattori N, Nagamatsu M, Ikeda Si, Ando Y, Nakazato M, Takei Yi, Hanyu N, Usui Y, Tanaka F, Harada T, Inukai A, Hashizume Y, Sobue G: Late-onset familial amyloid polyneuropathy type I (transthyretin Met30-associated familial amyloid polyneuropathy) unrelated to endemic focus in Japan. Clinicopathological and genetic features. Brain 1999, 122:1951-1962

9. Sousa MM, Cardoso I, Fernandes R, Guimarães A, Saraiva MJ: Deposition of transthyretin in early stages of familial amyloidotic polyneuropathy: evidence for toxicity of nonfibrillar aggregates. Am J Pathol 2001, 159:1993-2000

10. Sousa MM, Du Yan S, Fernandes R, Guimaraes A, Stern D, Saraiva MJ: Familial amyloid polyneuropathy: receptor for advanced glycation end products-dependent triggering of neuronal inflammatory and apoptotic pathways. J Neurosci 2001, 21:7576-7586

11. Gonçalves NP, Teixeira-Coelho M, Saraiva MJ: The inflammatory response to sciatic nerve injury in a familial amyloidotic polyneuropathy mouse model. Exp Neurol 2014, 257:76-87

12. Hulpiau P, van Roy F: Molecular evolution of the cadherin superfamily. Int J Biochem Cell Biol 2009, 41:349-369

13. Hayashi S, Inoue Y, Kiyonari H, Abe T, Misaki K, Moriguchi H, Tanaka Y, Takeichi M: Protocadherin-17 mediates collective axon extension by recruiting actin regulator complexes to interaxonal contacts. Dev Cell 2014, 30:673-687

14. Jao TM, Tsai MH, Lio HY, Weng WT, Chen CC, Tzeng ST, Chang CY, Lai YC, Yen SJ, Yu SL, Yang YC: Protocadherin 10 suppresses tumorigenesis and metastasis in colorectal cancer and its genetic loss predicts adverse prognosis. Int J Cancer 2014, 135: 2593-2603

15. van Roy F: Beyond E-cadherin: roles of other cadherin superfamily members in cancer. Nat Rev Cancer 2014, 14:121-134

16. Dibbens LM, Tarpey PS, Hynes K, Bayly MA, Scheffer IE, Smith R, et al: X-linked protocadherin 19 mutations cause femalelimited epilepsy and cognitive impairment. Nat Genet 2008, 40: 776-781

17. Lachman HM, Petruolo OA, Pedrosa E, Novak T, Nolan K, Stopkova P: Analysis of protocadherin alpha gene deletion variant in bipolar disorder and schizophrenia. Psychiatr Genet 2008, 18:110-115

18. Morrow EM, Yoo SY, Flavell SW, Kim TK, Lin Y, Hill RS, Mukaddes NM, Balkhy S, Gascon G, Hashmi A, Al-Saad S, Ware J, Joseph RM, Greenblatt R, Gleason D, Ertelt JA, Apse KA, Bodell A, Partlow JN, Barry B, Yao H, Markianos K, Ferland RJ, Greenberg ME, Walsh CA: Identifying autism loci and genes by tracing recent shared ancestry. Science 2008, 321:218-223

19. Kim SY, Yasuda S, Tanaka H, Yamagata K, Kim H: Non-clustered protocadherin. Cell Adh Migr 2011, 5:97-105

20. Hayashi S, Takeichi M: Emerging roles of protocadherins: from selfavoidance to enhancement of motility. J Cell Sci 2015, 128:1455-1464

21. Uemura M, Nakao S, Suzuki ST, Takeichi M, Hirano S: OL-Protocadherin is essential for growth of striatal axons and thalamocortical projections. Nat Neurosci 2007, 10:1151-1159 
22. Tsai NP, Wilkerson JR, Guo W, Maksimova MA, DeMartino GN, Cowan CW, Huber KM: Multiple autism-linked genes mediate synapse elimination via proteasomal degradation of a synaptic scaffold PSD-95. Cell 2012, 151:1581-1594

23. Li Z, Yang Z, Peng X, Li Y, Liu Q, Chen J: Nuclear factor- $\kappa B$ is involved in the protocadherin-10-mediated pro-apoptotic effect in multiple myeloma. Mol Med Rep 2014, 10:832-838

24. Kohno K, Palha JA, Miyakawa K, Saraiva MJ, Ito S, Mabuchi T, Blaner WS, Iijima H, Tsukahara S, Episkopou V, Gottesman ME, Shimada K, Takahashi K, Yamamura K, Maeda S: Analysis of amyloid deposition in a transgenic mouse model of homozygous familial amyloidotic polyneuropathy. Am J Pathol 1997, 150:1497-1508

25. Santos SD, Fernandes R, Saraiva MJ: The heat shock response modulates transthyretin deposition in the peripheral and autonomic nervous systems. Neurobiol Aging 2010, 31:280-289

26. Abbate A, Salloum FN, Vecile E, Das A, Hoke NN, Straino S, Biondi-Zoccai GG, Houser JE, Qureshi IZ, Ownby ED, Gustini E, Biasucci LM, Severino A, Capogrossi MC, Vetrovec GW, Crea F, Baldi A, Kukreja RC, Dobrina A: Anakinra, a recombinant human interleukin-1 receptor antagonist, inhibits apoptosis in experimental acute myocardial infarction. Circulation 2008, 117:2670-2683

27. Salloum FN, Chau V, Varma A, Hoke NN, Toldo S, BiondiZoccai GG, Crea F, Vetrovec GW, Abbate A: Anakinra in experimental acute myocardial infarction-does dosage or duration of treatment matter? Cardiovasc Drugs Ther 2009, 23:129-135

28. Gonçalves NP, Vieira P, Saraiva MJ: Interleukin-1 signaling pathway as a therapeutic target in transthyretin amyloidosis. Amyloid 2014, $21: 175-184$

29. Semple SC, Akinc A, Chen J, Sandhu AP, Mui BL, Cho CK, et al: Rational design of cationic lipids for siRNA delivery. Nat Biotechnol 2010, 28:172-176

30. Brumovsky PR, Bergman E, Liu HX, Hökfelt T, Villar MJ: Effect of a graded single constriction of the rat sciatic nerve on pain behavior and expression of immunoreactive NPY and NPY Y1 receptor in DRG neurons and spinal cord. Brain Res 2004, 1006:87-99

31. Furuya H, Saraiva MJ, Gawinowicz MA, Alves IL, Costa PP, Sasaki H, Goto I, Sakaki Y: Production of recombinant human transthyretin with biological activities toward the understanding of the molecular basis of familial amyloidotic polyneuropathy (FAP). Biochemistry 1991, 30:2415-2421

32. Teixeira PF, Cerca F, Santos SD, Saraiva MJ: Endoplasmic reticulum stress associated with extracellular aggregates. Evidence from transthyretin deposition in familial amyloid polyneuropathy. J Biol Chem 2006, 281:21998-22003

33. Ferreira N, Saraiva MJ, Almeida MR: Natural polyphenols inhibit different steps of the process of transthyretin (TTR) amyloid fibril formation. FEBS Lett 2011, 585:2424-2430

34. Monteiro FA, Sousa MM, Cardoso I, do Amaral JB, Guimarães A, Saraiva MJ: Activation of ERK1/2 MAP kinases in familial amyloidotic polyneuropathy. J Neurochem 2006, 97:151-161

35. Yoshimura R, Kyuka A, Jinno M, Nishio S, Matsusaka M, Nishida T, Endo Y: Increase in neuropilin-1 on the surface of growth cones and putative raft domains in neuronal NG108-15 cells co-cultured with vascular smooth muscle SM-3 cells. J Membr Biol 2015, 248: $171-178$

36. Cardoso I, Brito M, Saraiva MJ: Extracellular matrix markers for disease progression and follow-up of therapies in familial amyloid polyneuropathy V30M TTR-related. Dis Markers 2008, 25:37-47

37. Sousa MM, Yan SD, Stern D, Saraiva MJ: Interaction of the receptor for advanced glycation end products (RAGE) with transthyretin triggers nuclear transcription factor $\mathrm{kB}(\mathrm{NF}-\mathrm{kB})$ activation. Lab Invest 2000, 80:1101-1110

38. Halbleib JM, Nelson WJ: Cadherins in development: cell adhesion, sorting, and tissue morphogenesis. Genes Dev 2006, 20:3199-3214

39. Andreyeva A, Nieweg K, Horstmann K, Klapper S, MüllerSchiffmann A, Korth C, Gottmann K: C-terminal fragment of
$\mathrm{N}$-cadherin accelerates synapse destabilization by amyloid-beta. Brain 2012, 135:2140-2154

40. Zuo T, Qin JY, Chen J, Shi Z, Liu M, Gao X, Gao D: Involvement of $\mathrm{N}$-cadherin in the protective effect of glial cell line-derived neurotrophic factor on dopaminergic neuron damage. Int J Mol Med 2013, 31:561-568

41. Hirano S, Yan Q, Suzuki ST: Expression of a novel protocadherin, OL-protocadherin, in a subset of functional systems of the developing mouse brain. J Neurosci 1999, 19:995-1005

42. Hoshina N, Tanimura A, Yamasaki M, Inoue T, Fukabori R, Kuroda T, Yokoyama K, Tezuka T, Sagara H, Hirano S, Kiyonari H, Takada M, Kobayashi K, Watanabe M, Kano M, Nakazawa T, Yamamoto T: Protocadherin 17 regulates presynaptic assembly in topographic corticobasal Ganglia circuits. Neuron 2013, 78:839-854

43. Xu Y, Yang Z, Yuan H, Li Z, Li Y, Liu Q, Chen J: PCDH10 inhibits cell proliferation of multiple myeloma via the negative regulation of the Wnt/ $\beta$-catenin/BCL-9 signaling pathway. Oncol Rep 2015, 34: $747-754$

44. Liz MA, Mar FM, Santos TE, Pimentel HI, Marques AM, Morgado MM, Vieira S, Sousa VF, Pemble H, Wittmann T, Sutherland C, Woodgett JR, Sousa MM: Neuronal deletion of GSK3 $\beta$ increases microtubule speed in the growth cone and enhances axon regeneration via CRMP-2 and independently of MAP1B and CLASP2. BMC Biol 2014, 12:47

45. Murakami T, Sango K, Watabe K, Niimi N, Takaku S, Li Z, Yamamura K, Sunada Y: Schwann cells contribute to neurodegeneration in transthyretin amyloidosis. J Neurochem 2015, 134:66-74

46. Nakao S, Platek A, Hirano S, Takeichi M: Contact-dependent promotion of cell migration by the OL-protocadherin-Nap1 interaction. J Cell Biol 2008, 182:395-410

47. Chen B, Brinkmann K, Chen Z, Pak CW, Liao Y, Shi S, Henry L, Grishin NV, Bogdan S, Rosen MK: The WAVE regulatory complex links diverse receptors to the actin cytoskeleton. Cell 2014, 156: 195-207

48. Chia PH, Chen B, Li P, Rosen MK, Shen K: Local F-actin network links synapse formation and axon branching. Cell 2014, 156: 208-220

49. Dent EW, Kalil K: Axon branching requires interactions between dynamic microtubules and actin filaments. J Neurosci 2001, 21: 9757-9769

50. Chia PH, Patel MR, Shen K: NAB-1 instructs synapse assembly by linking adhesion molecules and F-actin to active zone proteins. Nat Neurosci 2012, 15:234-242

51. Zhang C, Qiu HE, Krafft GA, Klein WL: Protein kinase C and F-actin are essential for stimulation of neuronal FAK tyrosine phosphorylation by G-proteins and amyloid beta protein. FEBS Lett 1996, 386:185-188

52. Scarlato M, Ara J, Bannerman P, Scherer S, Pleasure D: Induction of neuropilins-1 and -2 and their ligands, Sema3A, Sema3F, and VEGF, during Wallerian degeneration in the peripheral nervous system. Exp Neurol 2003, 183:489-498

53. Bannerman P, Ara J, Hahn A, Hong L, McCauley E, Friesen K, Pleasure D: Peripheral nerve regeneration is delayed in neuropilin 2-deficient mice. J Neurosci Res 2008, 86:3163-3169

54. Williams EO, Sickles HM, Dooley AL, Palumbos S, Bisogni AJ, Lin DM: Delta protocadherin 10 is regulated by activity in the mouse main olfactory system. Front Neural Circuits 2011, 5:9

55. Bondeva T, Wolf G: Role of neuropilin-1 in diabetic nephropathy. J Clin Med 2015, 4:1293-1311

56. Tendi EA, Cunsolo R, Bellia D, Messina RL, Paratore S, Calissano P, Cavallaro S: Drug target identification for neuronal apoptosis through a genome scale screening. Curr Med Chem 2010, 17:2906-2920

57. Macedo B, Batista AR, do Amaral JB, Saraiva MJ: Biomarkers in the assessment of therapies for familial amyloidotic polyneuropathy. Mol Med 2007, 13:584-591

58. Shi D, Murty VV, Gu W: PCDH10, a novel p53 transcriptional target in regulating cell migration. Cell Cycle 2015, 14:857-866 